PAULA CORREA

é professora

do Departamento

de Letras Clássicas

e Vernáculas

da FFLHC-USP
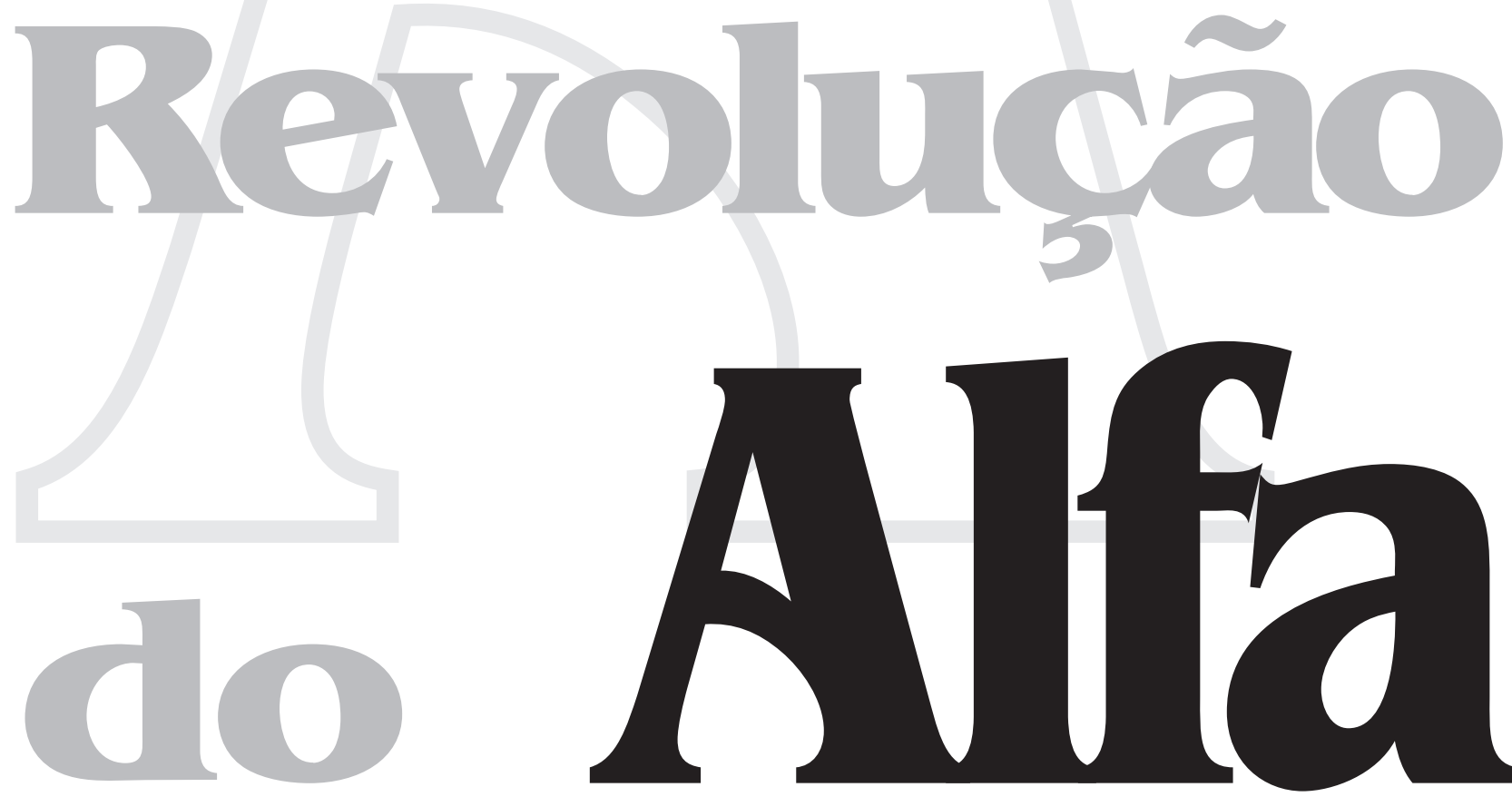

A Revolução da Escrita

na Grécia e suas

Conseqüências Culturais,

de Eric A. Havelock,

trad. Ordep J. Serra

Editora Unesp/Paz e

Terra, 1996.

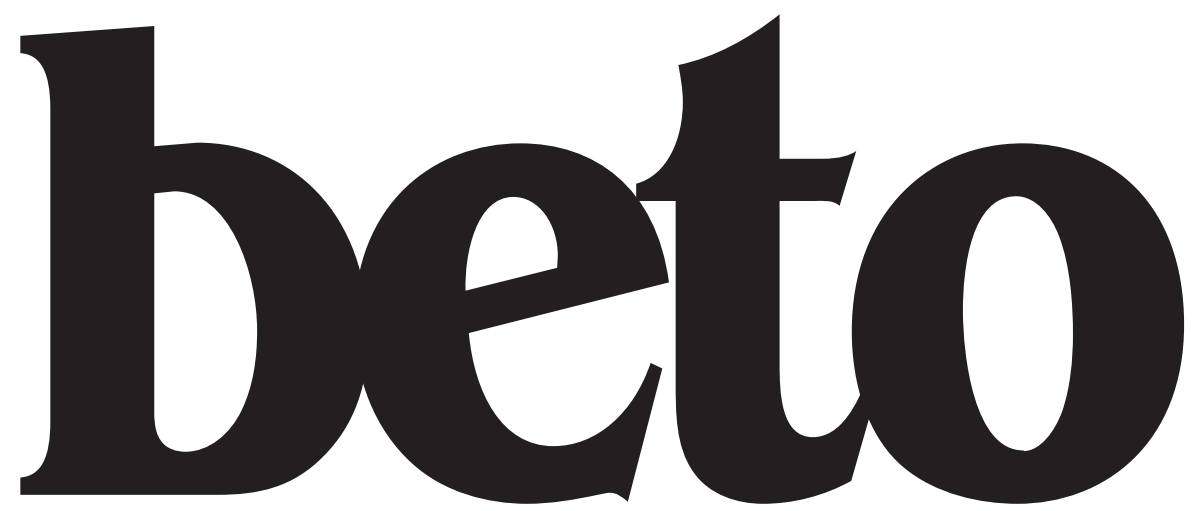




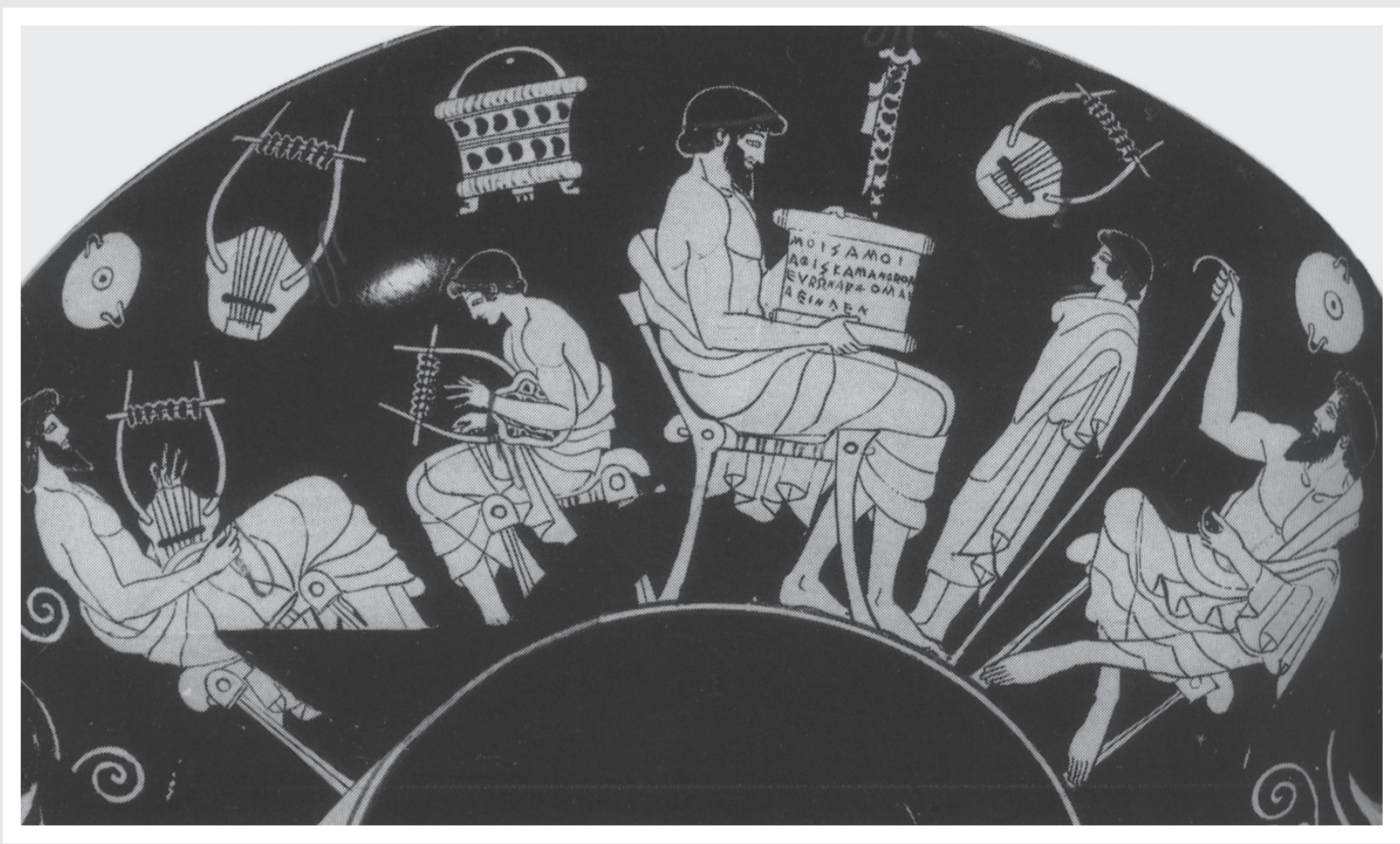

\section{PAULA CORREA}

Cena de escola ateniense, do início do séc. V a.C.

Como e para que fins a escrita foi reintroduzida na Grécia no VIII século a.C.? Qual foi seu impacto sobre a poesia oral e a cultura como um todo? Os poemas homéricos foram compostos com auxílio da escrita? Quais traços distinguem a linguagem oral da escrita? De que modo as formas de preservação e transmissão da cultura, as diversas escritas e técnicas mnemônicas podem influir sobre o seu próprio conteúdo? Estas são algumas das questões exploradas por Eric A. Havelock em A Revoluçao da Escrita na Grécia e suas Conseqüências Culturais.

Nunca houve tanto interesse pelas questões envolvendo oralismo e escrita como na segunda metade deste século; pesquisas e publicações de antropólogos, lingüistas e teóricos da comunicação se multiplicam. Exemplo disso até entre nós, onde novidades editoriais sofrem geralmente um atraso de dez a vinte anos, é o lançamento recente da coleção Múltiplas Escritas pela Editora Ática. Portanto, é oportuna a tradução deste livro que, reunindo uma série de ensaios e conferências publicadas de 1966 a 1980, está entre as principais obras de Havelock (1903-1988) (1), helenista cuja vida foi dedicada aos estudos sobre oralidade e cultura escrita na Grécia antiga.

Preface to Plato (Oxford 1963): Origins of Western Literacy (Toronto, 1976) Communication Arts in the Ancient World (ed.), E. A Havelock \& J. P. Hershbell (New York, 1978); The Literate Revolution in Greece and its Cultural Consequences (Princeton, 1982); The Muse Learns to Write: Reflections on Orality and Literacy from Antiquity to the Present (New Haven \& London, 1986). 


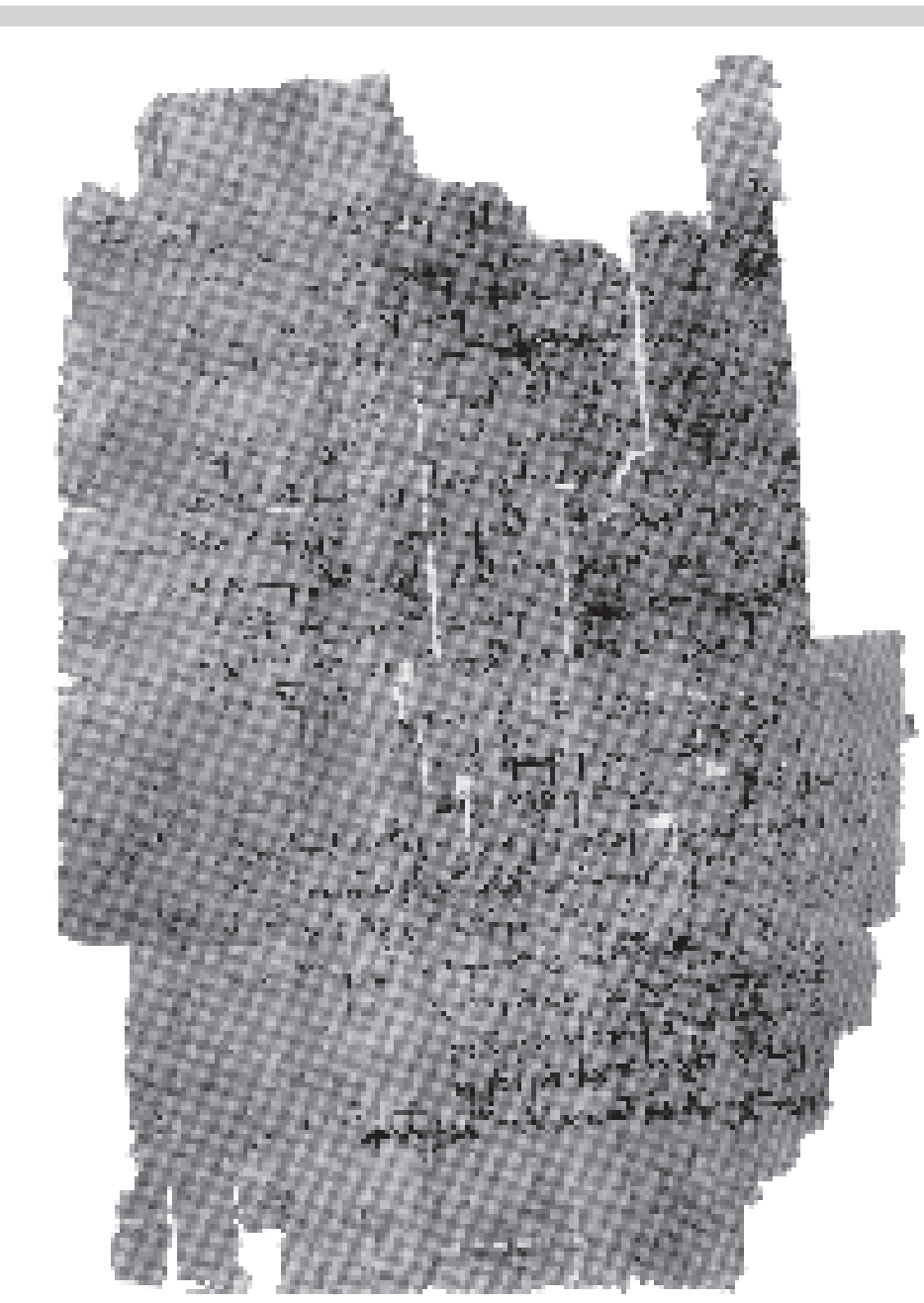

Papiro de música grega, do final do 2 o e começo do 3 o século a.C.

2 A. B. Lord, The Singer of Tales, Harvard, 1960.
Pioneiros nesse campo, que deram um novo rumo à célebre "questão homérica" $\mathrm{e}$ aos estudos sobre poesia grega antiga em geral, foram Milman Parry e Albert B. Lord, seu assistente. Investigando em sua tese de doutorado o epíteto tradicional em Homero (L'Épithète Tradicionelle dans Homère, Paris, 1928), Parry definiu a base do estilo dos poemas homéricos como formular e, nas décadas de 30-50, por meio do registro e estudo dos poemas épicos da tradição oral ainda viva entre os bardos servo-croatas, pôde comprovar suas hipóteses.

Parry concluiu que tanto o bardo grego antigo quanto o servo-croata, ao improvisar sua canção, serviam-se de um estoque de fórmulas definidas como unidades de duas ou mais palavras empregadas regularmente sob as mesmas condições métricas para expressar uma noção essencial. Preservadas e transmitidas ao longo dos séculos pela memória, as fórmulas constituíam um acervo comum, de uso e conhecimento coletivo, isto é, uma tradição oral. Assim, no decorrer de sua recitação, o bardo recorria a essa memória, selecionando e empregando as fórmulas tal como tijolos na construção do verso. Os epítetos (e outras fórmulas) não seriam portanto simples ornamentos ou auxílios à improvisação, eram elementos fundamentais da composição.

Baseando-se nesses mesmos princípios, Lord (2) deu prosseguimento à teoria da construção formular na poesia épica revelando que, além das fórmulas, os poetas de tradição oral dispunham de unidades maiores de composição, tal como as "expressões formulares" (formas fixas de meio ou até um verso composto de fórmulas) e os "temas", que não envolviam necessariamente a repetição de um grupo de palavras, mas de cenas típicas ou idéias, podendo estas ser abreviadas ou expandidas por elaboração.

Havelock, em palestra proferida no final de sua vida (1987) (3), revelou a grande influência que exerceram sobre ele Parry (cuja tese lera em 1943) e Lord, que divulgou o material recolhido por eles nos Bálcãs. Isso ocorreu após a Segunda Guerra Mundial, quando Havelock já era professor em Harvard, universidade com a qual Parry e Lord mantinham estreitos vínculos. Não obstante, os dois são considerados "predecessores" do que Havelock julgou ser o verdadeiro momento de ruptura, o divisor de águas nos estudos sobre a oralidade, marcado pela publicação de The Gutenberg Galaxy de McLuhan (1962), La Pensée Sauvage de Lévy-Strauss (1962), o artigo "The Consequences of Literacy" de J. Goody e I. Watt (1963), e o seu próprio Preface to Plato (1963).

Apesar das diversas abordagens e objetos específicos (o estudo da tecnologia da comunicação, dos mitos de culturas tribais não-letradas, e da tradição oral na Grécia antiga), Havelock vê nesse conjunto de pesquisas realizadas independentemente na França, Inglaterra, Estados Unidos e Canadá, o surgimento quase simultâneo de um 
interesse comum pela relação de "tensão mútua e criativa" existente entre oralidade e cultura escrita desde a invenção da escrita aos dias de hoje.

The Literate Revolution in Greece and its Cultural Consequences, título do livro de Havelock, não é de fácil tradução por não haver em português termo equivalente a literate. Pois literate não é exatamente "letrado" ou "literato", palavras que trazem consigo conotações de erudição e perícia. Segundo Havelock (1996, p. 60), uma cultura, para ser literate, depende da existência de documentos escritos e de um público constituído por indivíduos que tenham certa fluência na leitura, mas que não sejam forçosamente especialistas.

Três condições são apontadas por Havelock (1996, p. 64) como essenciais a uma escrita eficiente: 1) "o apanhado dos sons lingüísticos oferecido pelo sistema deve ser exaustivo"; 2) cada forma ou combinação de formas deve remeter a um só fonema, evitando a ambigüidade; 3) o número de formas deve ser limitado para não sobrecarregar a memória. A invenção do alfabeto no século VIII a.C., o "ancestral" das escritas européias modernas (a grega, a latina e a cirílica), representaria um salto tecnológico ao satisfazer todos esses quesitos.

As culturas que antecederam a grega (a chinesa, a egípcia e a mesopotâmica), apesar de possuírem sistemas de escrita, não seriam propriamente "letradas" mas "perito-letradas", devido às dificuldades de leitura criadas por suas escritas não-alfabéticas que, segundo Havelock (p. 60), restringiram a leitura a uma casta ou pequeno grupo habilitado. A própria Grécia, do oitavo aos meados do sex to século a.C., seria também "perito-letrada", passando a um período "semiletrado" de "recitação letrada” (no final do século VI ao V a.C.), à cultura "letrada escritural" do século IV a.C. (Havelock, p. 61).

A tese de Havelock é que, embora tal "revolução" não tenha ocorrido imediatamente após a criação do alfabeto grego, foi a sua invenção que permitiu que a escrita, antes restrita a elites, fosse democratizada pela primeira vez na Grécia antiga. Pois as dificuldades que os silabários "pré-alfabéticos" impunham aos seus leitores (mais decifradores que leitores, segundo Havelock) impossibilitavam a formação de culturas verdadeiramente "letradas".

A invenção da escrita alfabética e a relação desta com a cultura oral também teriam efeitos notáveis sobre a literatura grega arcaica e clássica. Inspirando-se em McLuhan ("o meio é a mensagem"), Havelock acreditava que a "limitação dos escritos pré-alfabéticos obstou a que seu conteúdo jamais alcançasse o padrão de sofisticação da arte literária grega e das literaturas pós-gregas" (1996, p. 15). Comparando duas descrições de um dilúvio, uma da Ilíada (XII, 17-33) e outra do Gilgamesh (cap. 8), ele sugeriu que a riqueza maior da narrativa grega (menos tautológica e ritualizada, mais complexa, de vocabulário e sintaxe mais variados e expressivos) resultava da superioridade do alfabeto grego sobre o cuneiforme para a transcrição dos poemas orais. Enquanto o alfabeto era capaz de reproduzir a recitação fielmente, o cuneiforme produzia um texto quase estenográfico (1996, p. 170):

“[...] na versão grega somos postos em contato direto com as complexidades da fala humana descritiva, em seu nível mais concreto; a versão babilônica, por contraste, simplifica o relato, reduzindo-o a um enunciado arquetípico, que pode ser chamado de "versão oficial"'.

Por outro lado, as próprias "deficiências" do cuneiforme, incapaz de registrar plenamente o discurso oral, tinham efeito negativo sobre o bardo: "não encorajaram o autor a condensar em seu verso uma plena variedade de expressão que uma descrição do tipo ensejado requer [...]" (Havelock, p. 170).

Outro aspecto desta "revolução da escrita" residiria na peculiaridade do alfabeto grego que "atomizava" os fonemas da língua. As escritas “pré-gregas”, mais empíricas, tentavam transcrever a língua "tal como ela é falada nas unidades silábicas” (p. 80). A grande novidade do alfabeto

\footnotetext{
3 E. A. Havelock, "A Equação Oralidade-Cultura Escrita: uma Fórmula para a Mente Moderna", in Cultura Escrito e Oralidade, D. R. Olson \& N. Torrance (eds.), trad. V. L. Siqueira, São Paulo, 1995 pp. 17-34
} 
grego seria a análise destas unidades silábicas em dois elementos: a vogal (que pode existir sozinha na fala) e a consoante que é um "não-som", uma abstração. Esta operação efetuada pelo alfabeto teria promovido entre os gregos uma nova mentalidade analítica, fornecendo "a base conceitual para a construção das ciências e filosofias modernas", desenvolvimentos impossíveis aos povos de escritas ideogramáticas e silábicas (Havelock, pp. 12 e 15).

Vê-se que a concepção que Havelock tem da escrita grega, apresentada nesse livro detalhadamente nos capítulos 1-6e 12, e que permeia todos os demais, fundamentando suas teses mais amplas tanto sobre a cultura escrita quanto a oral, é problemática e requer exame.

Além da teleologia, evidente em toda obra de Havelock, transparece em suas análises das escritas "pré-gregas" um acerbado preconceito. Entre essas escritas, o estatuto de alfabeto é negado inclusive ao fenício, considerado por Havelock como uma escrita silábica, "pré-alfabética”. A posição de Havelock é, no mínimo, controvertida. Ambas as teses, pró ou contra a definição da escrita fenícia como um alfabeto, contam com um número considerável de defensores. Estamos longe de um consenso. Mas como notou Rosalind Thomas (4), o debate sobre as origens do alfabeto grego às vezes "degenera na busca do primeiro inventor", o que se associa com um "chauvismo cultural". Vale a pena focalizar, a título de exemplo, uma passagem de Havelock que se encontra sob o sugestivo subtítulo "A Guerra das Escritas" (cap. 13, p. 337):

"Assim, as escritas que descendem dos silabários abreviados dos semitas do noroeste, desde a fenícia, passando pela aramaica, até a hebraica e a árabe, todas elas têm limitações que já foram descritas. Mas isso, por vezes, não impede os eruditos semitas de fazer proclamações da importância histórica e da relevância atual delas, protestos esses que parecem ter como meta esconder das vistas de todos o caráter único do invento grego, apresen- tando-o como um mero aperfeiçoamento, de alcance menor, de um sistema previamente elaborado, já foneticamente amadurecido. O moderno Estado de Israel envolveu-se num processo que haveria de reviver o hebraico tradicional, dando assim um exemplo de como uma escrita 'segue uma bandeira' [...]".

Consideremos, por contraste, as posições de outro ilustre helenista, Walter Burkert, em The Orientalizing Revolution: Near Eastern Influence on Greek Culture in the Early Archaic Age (Harvard, 1992):

"[...] the anti-oriental reflex was to prevail in the field which lay much closer to Hellenists, in the assessment of the Phoenicians, who had of old been regarded as the active intermediaries between the Orient and Hellas. Julius Beloch, a scholar of genius flawed by his idiosyncrasies and overt anti-Semitism, promulgated the theory that the significance of the Phoenicians in early Greece was close to zero $[\ldots]$... (p. 3).

"The most portentious achievement in Syria-Palestine was the development of the alphabetic script, which, through its ingenious simplification, made reading and writing more widely accessible for the first time. It was used equally by Hebrews, Phoenicians and Aramaeans. The invention goes back to the Bronze Age, but it gained its unique position only with the collapse of the Bronze Age, which made most of the other writing systems disappear" (p. 11).

Em “As Consequiências do Alfabeto”, último capítulo do livro, Havelock relativiza a "perfeição" do alfabeto grego notando que: 1) as 23 letras não são realmente exaustivas (os signos não representam fonemas únicos), o que acarreta ambigüidades e duplicação de funções; 2) as grafias não eram padronizadas e, apesar de o alfabeto tornar"automaticamente possível a leitura exata e fluente" do grego e do latim, ela ainda seria comparativamente lenta.

No entanto, Havelock continuou insistindo que a escrita grega não foi um "sim- 
ples aperfeiçoamento" do fenício, por meio da adaptação de signos para representar as vogais não marcadas nos sistemas semíticos. A sua invenção significaria uma verdadeira ruptura, uma "revolução". Se a escrita fenícia apresenta vantagens sobre outros silabários por possuir um número restrito de caracteres, para Havelock (p. 67) "não há como exagerar a lacuna técnica que se intercala entre estes sistemas e o grego".

Em resposta a isso, lingüistas já fizeram uma série de objeções. Em primeiro lugar, nosso conhecimento da escrita fenícia é ainda muito limitado, tanto do sistema em si, quanto de seus usos (5). Mesmo assim, percebe-se que, se na escrita fenícia as vogais não eram marcadas, isso não era tão necessário para sua eficiência quanto no sistema grego. Isso porque, na língua grega, podemos ter mais de uma vogal no meio da sílaba e os sufixos das declinações terminam freqüentemente em vogais, o que torna sua transcrição muitas vezes imprescindível para um reconhecimento correto da morfologia e sintaxe (Thomas, 1992, p. 55).

Por fim, não se pode dizer que o alfabeto seja um sistema de escrita "superior" aos demais em termos absolutos. A eficiência das escritas deve ser medida com referência à transcrição de sua própria língua. Assim, já se provou que o alfabeto não é o sistema mais adequado para a transcrição de certas línguas (cf. Thomas, 1996, p. 17) e, se ele se espalhou, sendo adotado por outras culturas, tal fato se deve mais a fatores políticos e econômicos que a suas qualidades intrínsecas.

Muitas críticas e correções às teses de Havelock já foram feitas por lingüistas, antropólogos e helenistas. Não seria possível estender ou retomá-las todas aqui. Elas refletem, por sua vez, a originalidade do trabalho de Havelock e o grande impacto que exerceu sobre os estudos clássicos nos últimos trinta anos. Herdeiro de Parry e Lord, talvez seu maior mérito tenha sido chamar a atenção para o aspecto essencialmente oral da cultura e literatura grega, cujas obras eram antes lidas e estudadas como se fossem textos de escritores modernos. Por investigar pela primeira vez uma série de questões e problemas que envolvem a relação da tradição oral e a introdução da escrita na Grécia antiga, dando início a controvérsias e debates, a contribuição de Havelock é valiosa, suas obras já sendo consideradas clássicos.

Estela funerária.

Começo

do séc. IV a.C.

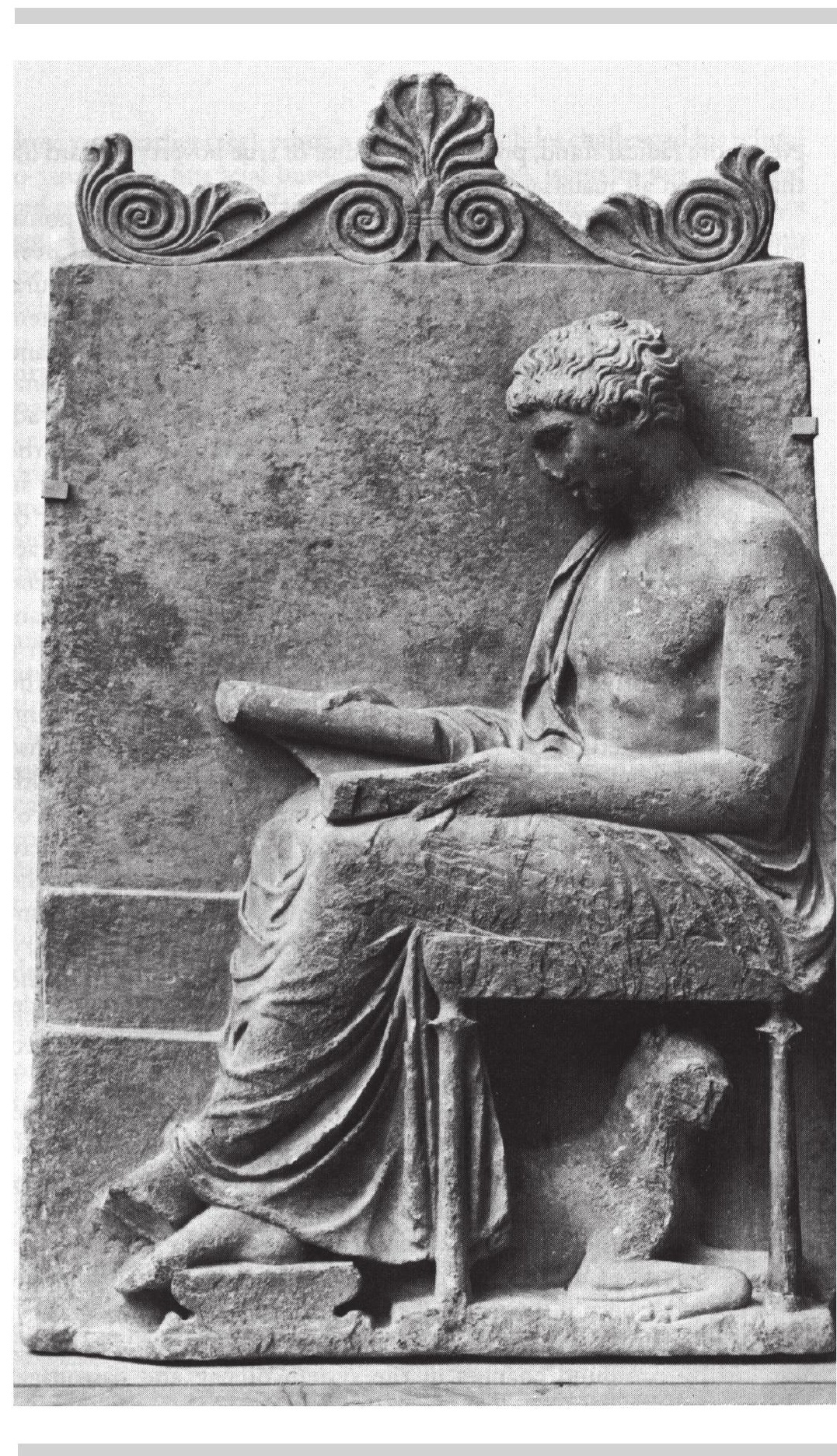

